\section{LNGFlow Dashboard April 2020}

In April, LNG imports in China grew 1.06 MT-or 25 percent year on year compared to the 9 and 6 percent drops seen in January and February. Elsewhere in Asia, however, imports in Japan, Korea, and Taiwan (JKT) dropped to $9.6 \mathrm{MT}$-a 20 percent drop from March and a 4 percent decrease year on year. European imports are still up year on year at 7 percent, though this is significantly less than in previous months.

Global LNG supply reached 31 MT, the lowest level in ten months and a 6 percent decline from March. The decline in supply came from Qatar and Malaysia, which supplied 0.7 and $0.5 \mathrm{MT}$ less than in March, respectively. Finally, US projects exported $4.3 \mathrm{MT}$, which was the lowest level in six months.
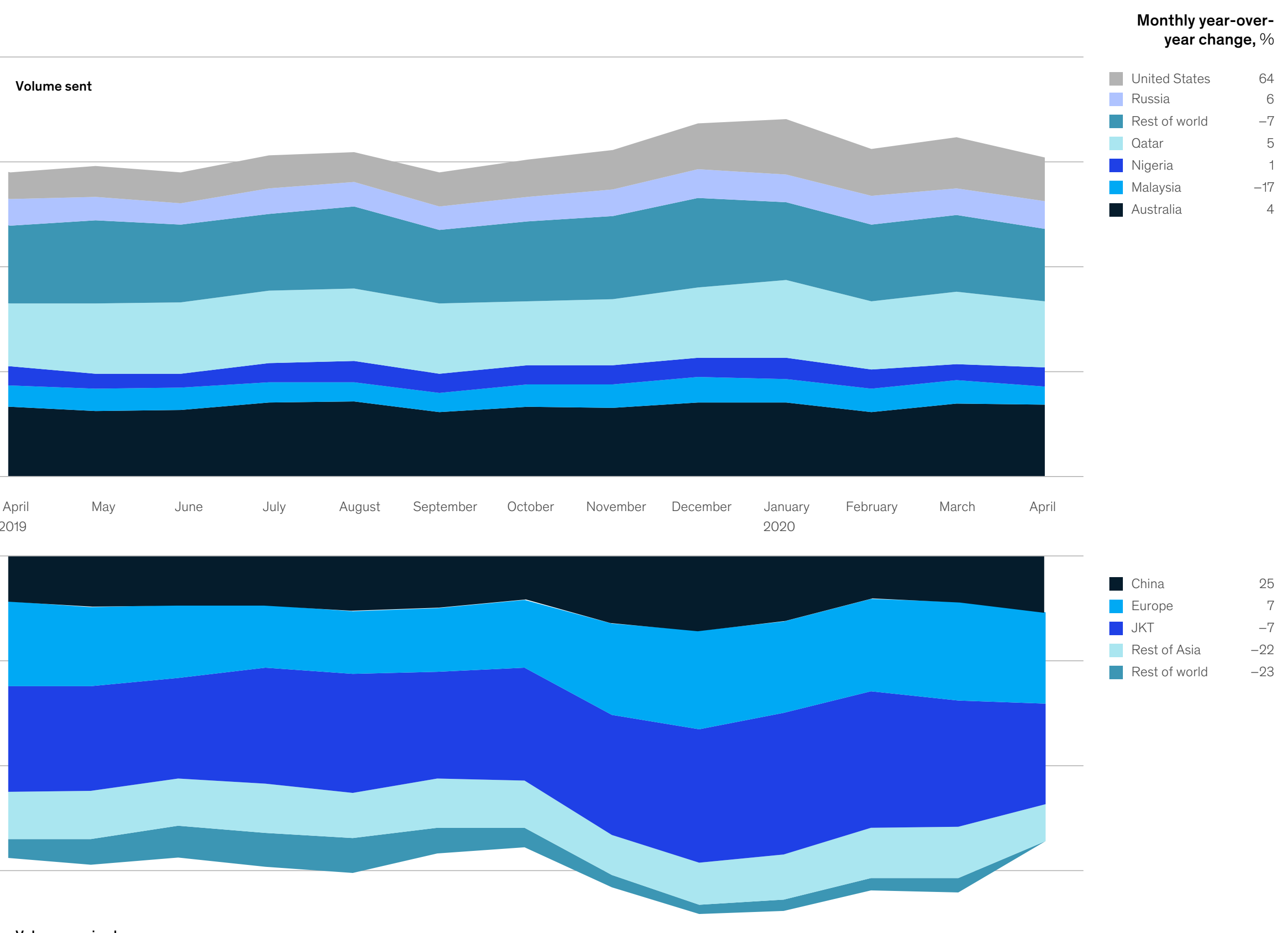

China
Europe
JKT
Rest of

Rest of Asia

Rest of world $\quad-23$
LNG flows by contract type, monthly deliveries

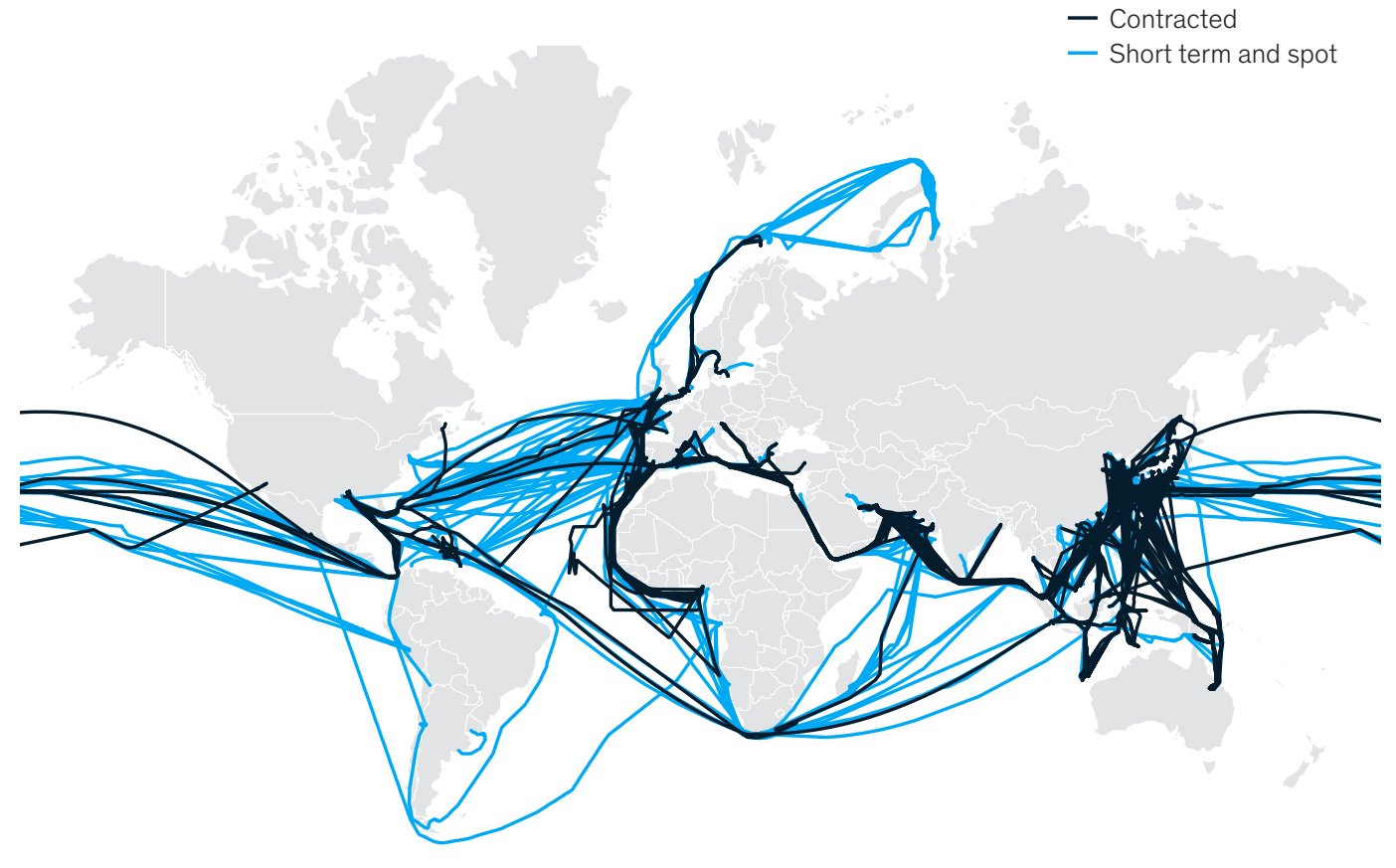

Liquidity, \%

\section{"IIIIIIIIIII!'}

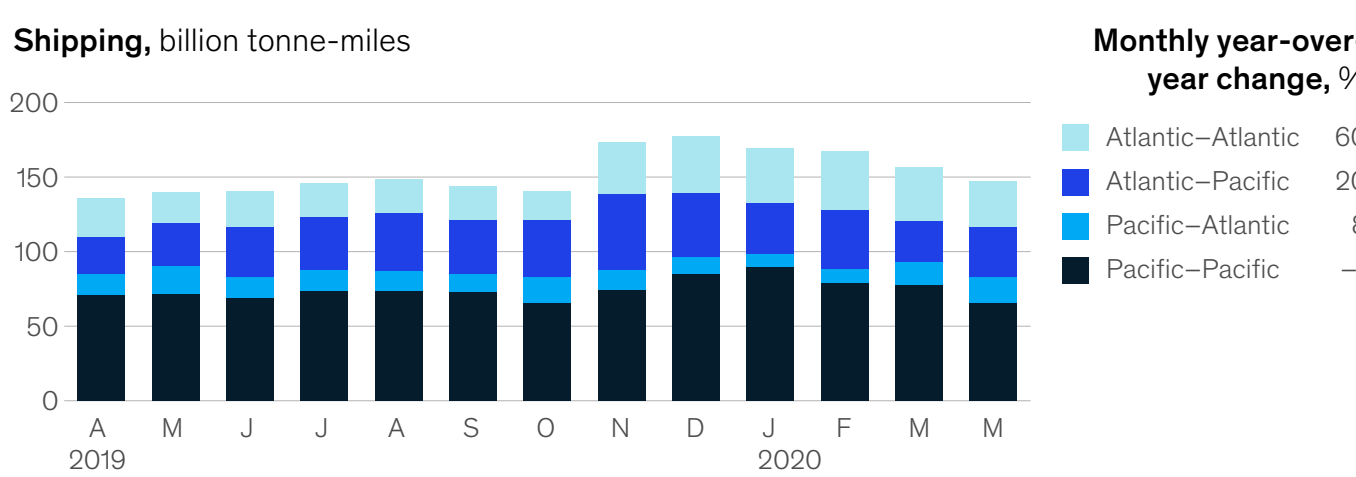

McKinsey

\& Company

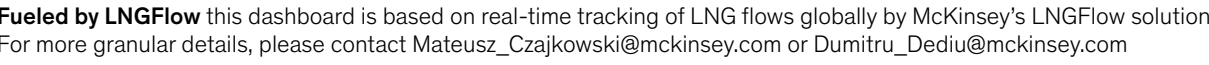

Source: Mckinsey's Energy Insights LNGFlow; Vesseltrackerø, powered by Genscape 